\title{
COVID-19 Self-quarantine and Weight Gain Risk Factors in Adults
}

\author{
Zachary Zeigler ${ }^{1}$ (iD \\ Accepted: 11 June 2021 / Published online: 12 July 2021 \\ (C) The Author(s), under exclusive licence to Springer Science+Business Media, LLC, part of Springer Nature 2021
}

\begin{abstract}
Purpose of Review The COVID-19 pandemic is associated with weight gain in certain individuals. This review highlights the risk factors for weight gain during COVID-19 self-quarantine in adults.

Recent Findings Among those who have gained weight during COVID-19 self-quarantine, self-reported body weight has increased between .5 and $1.8 \mathrm{~kg}( \pm 2.8 \mathrm{~kg})$ after just 2 months of quarantine. Identified risk factors for weight gain during COVID-19 self-quarantine are the following: increased sedentary behaviors, decreased physical activity, increased snacking frequency (particularly after dinner), increased alcohol intake, decreased water intake, emotional eating, decreased sleep quality, and being overweight/obese.

Summary Having identified risk factors for weight gain during the COVID-19 pandemic, practitioners and researchers should devise plans to assist those who have gained weight to re-learn weight management/weight loss strategies.
\end{abstract}

Keywords COVID-19 $\cdot$ Pandemic $\cdot$ Self-quarantine $\cdot$ Weight gain

\section{Introduction}

On January 30, 2020, the WHO declared the severe acute respiratory syndrome coronavirus 2 (SARS-CoV2 ), the virus that causes the novel coronavirus disease 2019 (COVID-19) pandemic, a global health emergency [1]. Statistical modeling indicated that without mitigation, COVID-19 would have afflicted more than $60 \%$ of the US population [2]. Many health organizations such as the US Centers for Disease Control and Prevention [3] and the WHO [1] have issued safety recommendations to reduce exposure to and transmission of the virus. Social distancing, self-quarantine, and widespread shutdowns were imposed to flatten the epidemic curve. The hope was to curb the effects the virus may have had on the healthcare system, morbidity, and mortality [4]. This directive caused grade schools, universities, parks, gyms, and any non-essential business to close. Nonetheless, roughly 12 months after the first

This article is part of the Topical Collection on Etiology of Obesity

Zachary Zeigler

Zachary.zeigler@gcu.edu

1 College of Science Engineering and Technology, Grand Canyon University, 19013 W Solano Dr. Litchfield Park,

Phoenix, AZ 85340, USA lockdown was announced, COVID-19 mitigation strategies continue.

The extended self-quarantine, widespread shutdown duration, and adverse psychological reactions to the pandemic have brought speculation of an unintended consequence of weight gain [5-7]. The literature has revealed both weight gain and weight loss during COVID-19 self-quarantine [8, 9]. After 2 months of COVID-19 lockdowns, for those reporting weight gain, self-reported body weight increased anywhere between .5 and $1.8 \mathrm{~kg}$ [7, 10-12]. Of greater significance, the weight-gain standard deviations are upwards of $2.8 \mathrm{~kg}$ [12]. Such large standard deviations suggest that some have gained roughly $11 \mathrm{~kg}$ during a relatively short time of self-quarantine imposed by the COVID-19 pandemic. This data collectively suggests that the COVID-19 pandemic provokes large amounts of weight gain in some but not all persons.

The unintended consequence of weight gain from COVID19 is of immense societal importance. Reports show that the COVID-19 virus more adversely impacts people with obesity than normal weight [13]. Thus, weight gain from COVID-19 self-quarantine could lead to a worsening COVID-19 prognosis. Furthermore, COVID-19 weight gain could be a catalyst for two public health pandemics colliding [14]. Numerous studies have now been published looking at weight gain risk factors from COVID-19 self-quarantine. Thus, the purpose of this review is to highlight the risk factors of weight gain during 
the COVID-19 pandemic in adults. For purposes of this article, data dealing with COVID-19 and weight gain in children will not be included.

\section{Physical Activity Behaviors}

Table 1 summarizes the amount of weight gained per study and the risk factors identified.

\section{Sedentary Behavior}

Researchers report an overall increase in sedentary behaviors during COVID-19 self-quarantine. A cross-sectional study of 37,252 participants from France found that $63.2 \%$ reported increased sedentary time, with an average of $7 \mathrm{~h}$ per day spent sitting during lockdown [10]. An online survey of 1047 participants encompassing Europe, North Africa, Western Asia, and the Americas revealed that COVID-19 home confinement had harmed all physical activity levels (vigorous, moderate, walking, overall), but the most notable change was a $28.6 \%$ increase in the hours per day sitting [15]. Increased sedentary behavior during COVID-19 self-quarantine can be, at least partially, caused by increased screen time. An observational study $(n=1970)$ from eighteen countries within the Middle East and North Africa showed that people spending more than 5 hours per day in front of a screen for entertainment purposes increased from a pre-COVID-19 level of 14.6 to $37.5 \%$ during the COVID-19 pandemic [16].

In addition, reports show an overall decrease in walking during COVID-19 self-quarantine [17]. Physical activity behavior data were released during the COVID-19 pandemic by Fitbit, Inc. This data included the average step counts of more than 30 million users and showed a significant decline in step count, which varied across nations, ranging from a 7 to $38 \%$ decrease during the week ending March 22, 2020, as compared with the same period last year [18].

Reports that ran regression models to determine predictors of weight gain during COVID-19 self-quarantine found that both increased television viewing and time spent in sedentary behaviors predicted weight gain $[8,10,19,20]$. For instance, in a Spanish sample $(n=1000)$, those who gained weight reported that one of the top reasons was decreased physical activity [21]. Additionally, in a study of 700 Chileans, it was shown that more than 6 hours per day of sedentary time predicted weight gain (OR: $1.85, p=0.01$ ) while active breaks were associated with weight loss (OR: $0.72, p=0.04)$ during the COVID-19 pandemic [8]. Pre-COVID-19 data has revealed that watching television is associated with increased snacking frequency of energy-dense foods, fast foods, and soda [22]. Thus, weight gain from screen time may be magnified by the unhealthy dietary habits that frequently accompany prolonged television viewing [23]. Moreover, a sedentary lifestyle may decrease resting energy expenditure by 10 to $50 \%$ [24].

\section{Exercise}

COVID-19 self-quarantine has negatively affected all physical activity levels (vigorous, moderate, overall) [15]. Large datasets from Australia $(n=5469)$, Spain $(n=2447)$, and France $(n=37,252)$ report that 43 to $61 \%$ of the population decreased physical activity during COVID-19 self-quarantine $[10,25,26]$. Additionally, it has been found that participants reporting decreased physical activity levels were also those reporting the longest time spent seated [10]. Thus, even though sedentary behavior and exercise are two separate confines concerning weight loss, COVID-19 self-quarantine may provoke parallel deleterious changes in both. Interestingly, some data suggest that those who maintained or increased physical activity during self-isolation were more than likely to have been active before the pandemic. For instance, a study of Italian participants ( $n=3533$ ) found that exercise frequency increased in those who already took part in sports while those who did not exercise prior did not start [27]. It could be that COVID-19 self-quarantine reinforced prior behaviors.

Regression models revealed that an overall decreased exercise volume was a predictor of weight gain during COVID19 self-quarantine [10,28]. Indeed, cross-sectional data $(n=$ 1970) from the Middle East and North Africa found that of those who trained more than three times per week, $25 \%$ lost weight during the pandemic, while $36 \%$ of those who trained less than this reported weight gain [16]. Additionally, within Lithuanian participants $(n=2447)$ who gained weight during the COVID-19 self-quarantine, $85.2 \%$ decreased their physical activity levels [25]. Conversely, the dataset from Chile revealed that exercising four or more days per week was associated with weight loss during the COVID-19 pandemic (OR: $0.51, p=0.001$ ) [8]. The ability of physical activity to halt weight gain is well supported [29]. Indeed, low physical activity levels negatively interact with body fat and appetite [30].

\section{Dietary Changes}

A healthy, planned diet is an integral part of personal risk management during pandemics such as COVID-19 [31]. It seems, however, that controlling total food intake during the COVID-19 pandemic has been problematic. Many studies show that those who gained weight during quarantine reported greater overall food intake $[12,21,25,28]$. Additionally, the diet quality of those who gained weight has changed negatively [21, 25, 32]. For instance, decreases in fruit and vegetable consumption $[16,25]$ and increases in sugary drink consumption $[21,25]$, as well as increased processed foods [21, 25], 


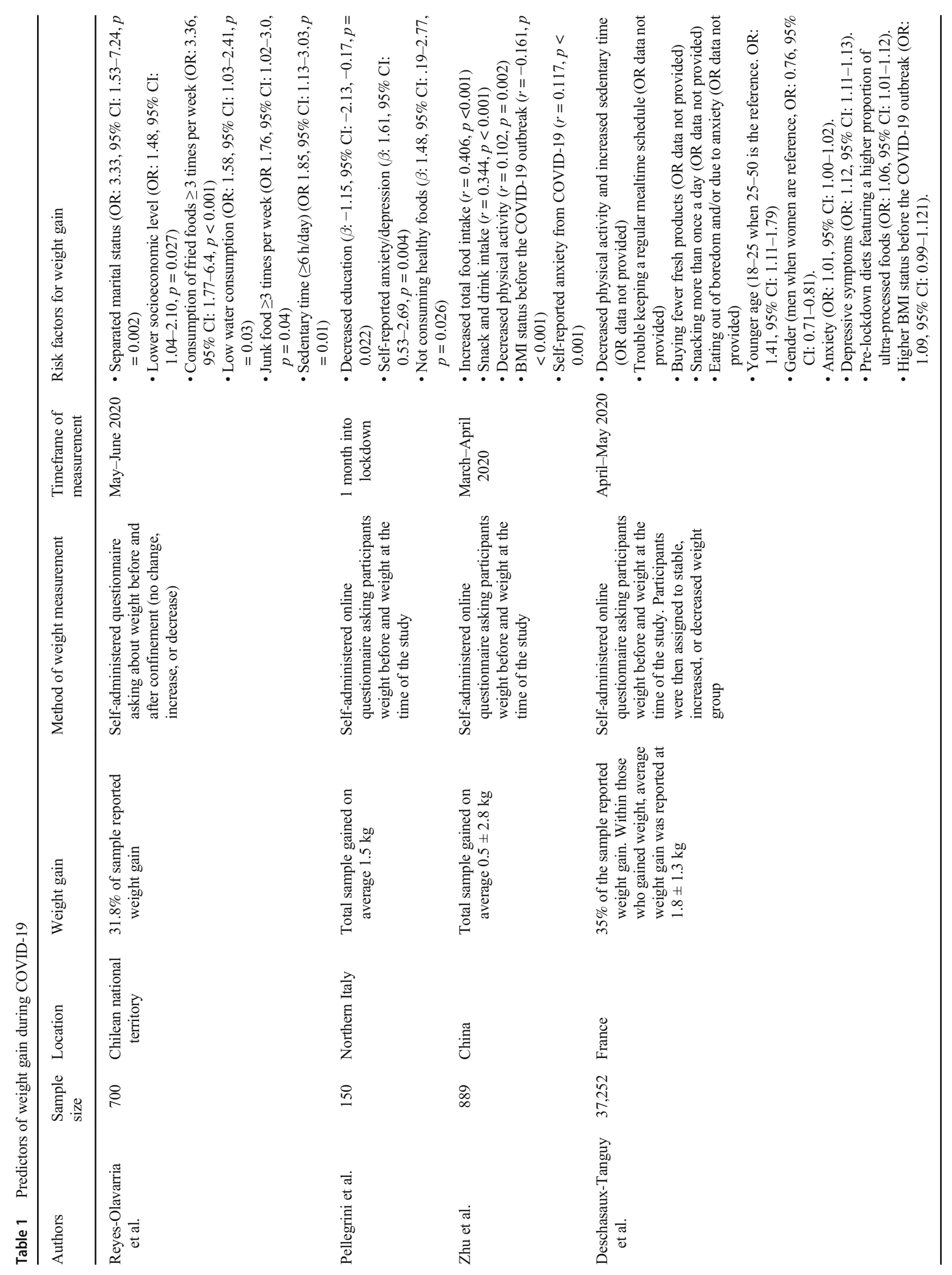




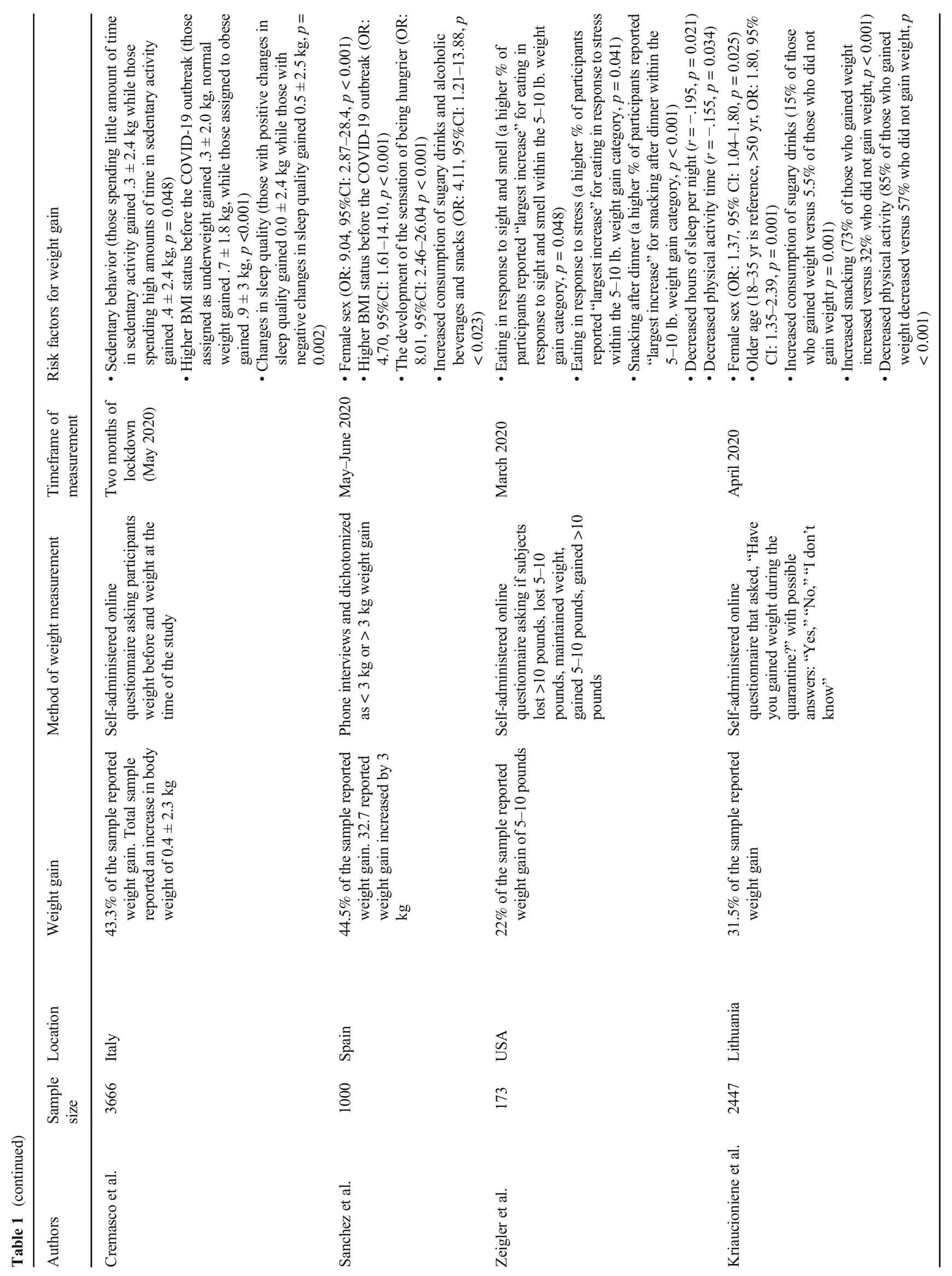




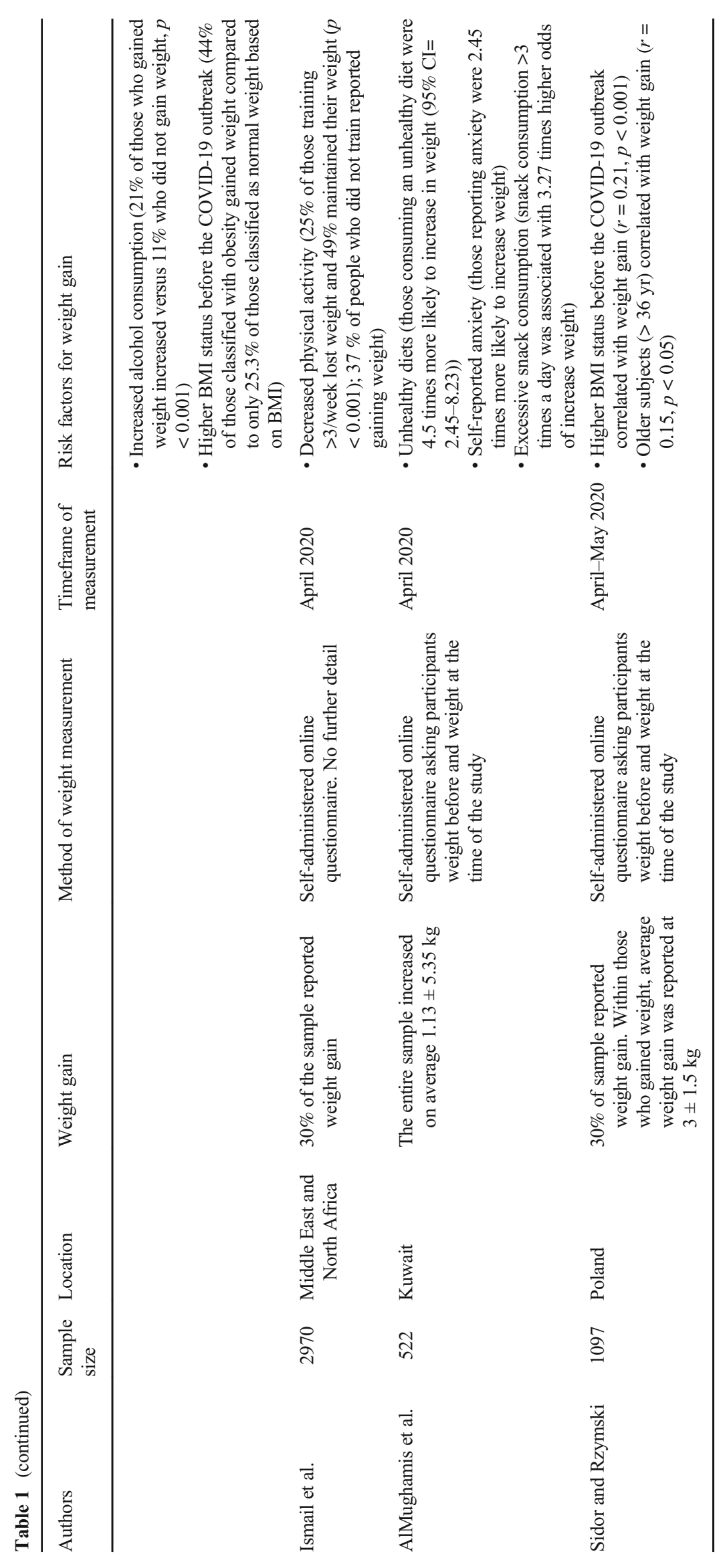


have all been reported within those who have gained weight during COVID-19 self-quarantine.

As will be discussed below, increased total caloric intake and increased intake of high-fat, high-sugar, processed foods could be due to the psychological impact the COVID-19 pandemic has been shown to have. Moreover, the type of food purchased during the COVID-19 pandemic has changed compared to pre-pandemic food purchasing [25]. For example, snack foods available during COVID-19 self-quarantine have been reported to change to foods that do not spoil. An article from the UK $(n=2002)$ found an $82 \%$ increase in unhealthy food in the home during COVID-19 self-quarantine [33]. Additionally, food consumption data from Italy $(n=10,769$ stores) reported that during the first 6 weeks of COVID-19 confinement, there was an increase in canned and frozen food consumption and decreased sales of fresh goods and fruits and vegetables [34]. Changing one's diet to adopt negative eating styles has been shown to predict weight gain during the COVID-19 pandemic. For instance, within a sample of 522 participants from Kuwait, compared with respondents who changed their diet pattern to healthier, those reporting unhealthy diets were 4.5 times more likely to report an increase in weight during COVID-19 self-quarantine [32].

Key essential nutrients have also been shown to be deficient during COVID-19 self-quarantine. One particular nutrient of concern in relation to the COVID-19 virus and risk of obesity is vitamin D. An extensive dataset from France revealed that lower intakes of vitamin D during COVID-19 self-quarantine were observed [10]. Vitamin D status is likely already strongly impacted by the lockdown due to increased time being spent indoors. Indeed, most vitamin D being produced is following sun exposure which is not compatible with the requirement to stay home. Furthermore, vitamin D is linked to both obesity and COVID-19 severity [35].

\section{Snacking}

The exact amount of caloric increase due to snacking is not provided in the literature. However, a commonly reported theme during COVID-19 self-quarantine is increased snacking frequency $[12,15,17,33,36]$. For example, crosssectional data from 1097 Poles revealed that $52 \%$ of participants admitted to snacking more frequently between meals when compared to before the pandemic [37]. Increased snacking may be problematic as pre-pandemic data reveals snacking leads to a positive energy balance [38]. Even a small positive energy balance over time is sufficient to cause weight gain in many individuals [39]. Indeed, increased snacking has been shown to predict weight gain during COVID-19 selfquarantine $[21,25]$. One report showed that consuming snacks greater than three times a day during COVID-19 selfquarantine was associated with 3.27 times higher odds of increasing weight than those consuming snacks less than three times a day [32].

Some studies have also reported that snacking, specifically after dinner, is an independent predictor of COVID-19 selfquarantine weight gain [28]. The link between snacking after dinner and weight gain is well supported in the literature. Emerging data has revealed that a high percentage of adipose tissue is diurnally regulated [40] and that calories consumed later in the day tend to be stored within adipose tissue [41].

\section{Water}

In many cases, water consumption during COVID-19 selfquarantine has been reported to have been reduced and often replaced with sugar-sweetened beverages [16, 27]. For instance, cross-sectional data $(n=1970)$ from the Middle East and North Africa revealed that $74 \%$ of people reported an inadequate water intake of fewer than eight cups per day [16]. Likewise, in Italy, $87 \%$ of surveyed participants reported drinking less than 21 of water per day, and $26 \%$ consumed less than 11 per day [27]. Moreover, regression analysis reveals that low water consumption is associated with body weight increase during the COVID-19 self-quarantine [8]. Indeed, an increased energy cost is associated with increasing the temperature of ingested water and changes in the osmolarity of the cell [42]. Furthermore, data suggest that water intake may impact the satiety response [43].

\section{Alcohol}

Whether or not alcohol intake has increased during COVID19 self-quarantine is somewhat controversial. Few studies reported increased alcohol consumption and higher drinking tendency among alcohol addicts [10,37], while other studies reported a decrease in binge drinking and alcohol consumption [9, 15, 27, 44]. Regardless, increased alcohol consumption is a predictor of weight gain during COVID-19 self-quarantine $[21,25]$. A sample of Spanish adults revealed that increased consumption of alcoholic beverages was an independent predictor of weight gain during COVID-19 self-quarantine (OR $4.11(1.21-13.99), p=0.023$ ) [21]. Additionally, researchers from Spain found that increase in alcohol consumption was reported by every fifth participant $(20.9 \%)$ who gained weight, and every tenth (11.2\%) who did not [25].

Increased alcohol consumption during the COVID-19 pandemic was linked with increased depression, anxiety, and stress during confinement in an Australian population [45]. Additionally, evidence has shown that alcohol drinkers are less likely to find anything positive about the COVID-19 pandemic situation and are mentally less able to cope [46]. Thus, alcohol intake may lead to weight gain during the COVID-19 pandemic because of its impact on emotional health. Also, given that $1 \mathrm{~g}$ of alcohol provides roughly 7 kilocalories of 
energy, it is no surprise that pre-pandemic prospective and longitudinal studies show that excessive alcohol consumption is associated with weight gain [47].

\section{Psychological Impacts on Eating}

Increased anxiety, stress, and depression during the COVID19 pandemic have all been reported [16, 48, 49]. Evidence suggests that the COVID-19 pandemic mandatory selfquarantine per se may trigger these psychological conditions [50]. In addition to self-quarantine, one's occupation [51], whether one has been diagnosed with COVID-19 [52], and misinformation [53] are other reported sources of stress and anxiety. Social media information overload may also provoke stress and anxiety. For instance, one study showed that $82 \%$ of participants were regularly exposed to social media, and the increase of exposure frequency was associated with higher odds of anxiety and depression [54].

Furthermore, food choice can be influenced by psychological parameters such as anxiety [55]. Pre-pandemic data suggest that negative emotions predict poor diet and increased intake of saturated fat, energy-dense, and salty foods [56]. Stress specifically can lead to hyperphagia, binge eating, and an alteration of the types of food eaten [57-59]. Pandemic data has revealed that higher stress scores predicted increased caloric intake (OR 1.07 (1.05-1.10), $p<0.001)$ [44]. Additionally, data from a Spanish population revealed that $74 \%$ of respondents confessed to having experienced more significant and frequent sensations of hunger than before the lockdown, with anxiety as the top factor related to this perception of increased hunger [21]. These authors reported that the development of hunger sensation was an independent predictor of weight gain (OR $8.01(2.46-26.04), p<0.001)$.

Additional data from France revealed that those who gained weight had higher depression and anxiety scores [10]. Further data from Kuwait reported that those with anxiety throughout the day were 2.45 times more likely to increase weight than those never experiencing it during the COVID-19 pandemic [32]. In a sample of 889 participants in China, anxiety from COVID-19 self-quarantine was shown to be a strong predictor of eating and eventual weight gain [12]. Even among obese patients receiving nutritional advice for at least 6 months before the pandemic, those with self-reported anxiety and depression gained more weight than those without during the COVID-19 self-quarantine $(3.18 \mathrm{~kg}$ vs. $0.49 \mathrm{~kg}, p<0.001)$ [7].

Adverse changes in eating behavior could also be due to eating out of boredom. Indeed, boredom has been shown to predict negative eating behaviors [60] and is associated with increased eating during the COVID-19 pandemic [28]. Boredom, stress, anxiety, and depression may lead to emotional eating, contributing to weight gain [61]. For instance,
640 pregnant women in China were asked about emotional eating indices and gestational weight gain during the COVID19 pandemic [62]. It was found that women who showed a more significant concern about the COVID-19 pandemic had higher emotional eating scores and an increased risk of excess gestational weight gain (OR 1.90 (1.08-3.32), $p<0.001)$.

\section{Demographic Predictors of Weight Gain}

\section{BMI}

The literature is robust in that nearly every study addressing predictors of weight gain during COVID-19 self-quarantine identifies that individuals categorized as overweight or obese are at higher risk of weight gain [7, 10, 21, 25, 33]. For example, in a sample of 2447 participants from Lithuania, $25.3 \%$ of those whose BMI falls within normal $\left(18.5-24.9 \mathrm{~kg} / \mathrm{m}^{2}\right)$, $39.3 \%$ of those whose BMI falls within overweight (25-29.9 $\mathrm{kg} / \mathrm{m}^{2}$ ), and $43.6 \%$ of those whose BMI falls within the obese $\left(>30 \mathrm{~kg} / \mathrm{m}^{2}\right)$ category reported weight gain during the COVID-19 self-quarantine [25]. There are many hypotheses as to why individuals with obesity gain disproportionately during COVID-19 self-quarantine. One hypothesis is that individuals with obesity have pre-established habits of buying and consuming calorically dense, processed foods, which are exacerbated by the COVID-19 pandemic. For instance, data from across the USA during COVID-19 self-quarantine showed that populations with a higher percentage of adults with obesity showed greater patronage of unhealthy eating establishments [63]. Pre-pandemic data has shown that areas with a higher density of establishments selling high-calorie fast food and junk food relative to healthier options relate to obesity [64]. Additionally, a sample of 1030 Dutch adults found that people with overweight or obesity report it more challenging to make healthy food choices during COVID-19 lockdown than normal-weight persons [65]. Indeed, having a higher BMI has been associated with increased junk food consumption during COVID-19 self-isolation [37, 63]. PreCOVID-19 pandemic literature reports that the obese display more problematic eating behaviors such as frequent eating without hunger and eating when bored or lonely, compared to lean $[60,66]$. These problematic eating behaviors may be partly due to the higher risk for social isolation and depression during COVID-19 reported in the obese population [14]. COVID-19 data also has revealed that BMI is positively associated with increased appetite after dinner [27]. Late-night snacking, as previously discussed, is an independent predictor of weight gain.

The association between obesity and unhealthy eating during COVID-19 self-quarantine could be moderated by stress [65]. Prior research has demonstrated that stress is associated with obesity and that individuals with obesity are more prone 
to stress-induced eating than healthy controls [67]. In addition, those with obesity may also experience stress from weight stigma. Evidence shows that weight stigma affects weightrelated health, including lower physical activity and unhealthy eating behaviors and weight gain [68]. Although data suggests those with obesity did not experience increased weight stigma during the COVID-19 pandemic [69], 19-42\% of individuals with obesity are discriminated against because of their weight [70]. Indeed, the odds of engaging in binge eating during COVID-19 were nearly three times higher for individuals teased about their weight before the pandemic than those never teased about their weight [71].

\section{Gender}

Gender is not a consistent predictor of weight gain during COVID-19 self-quarantine, with some studies reporting no gender differences [12, 27, 37], while others report increased weight gain in women $[10,21,25]$. Using a Spanish sample, researchers reported that the most critical factor related to weight gain was the female gender, with $58 \%$ of women versus $46 \%$ of men reporting weight gain during COVID-19 selfquarantine [21]. During COVID-19 self-quarantine, females may have a higher risk than males of atypical sleep levels [72]. Additionally, more females than males have self-reported that it is harder to make healthy food choices during selfquarantine [65]. Females also report greater calorie/salty food intake and increased screen time during COVID-19 self-quarantine when compared to males [44]. Increased weight gain among women could also be attributed to their smaller bodies and lower caloric requirements - relative to typical food portions [21].

\section{Age}

The impact of age within the adult population on weight gain during the COVID-19 pandemic is unclear. Some datasets show that age does not affect weight gain $[12,25]$, while some suggest age is a moderating variable [37,65]. Two studies confirmed that the eating behaviors of older participants ( 65 years and up) were less likely to change than those of younger adults $[65,72]$. On the other hand, a lower age was associated with increased junk food consumption [37, 63] and increased overall appetite during COVID-19 self-quarantine [27]. More data on the possible moderating role of age on COVID-19 self-quarantine weight gain are warranted.

\section{Socio-economic Status}

Socio-economic status is another variable that is not entirely consistent in the literature. Some studies suggest that monthly income and education did not predict COVID-19 self-quarantine weight gain $[12,37]$, while a few studies contradicted these findings [7,33]. Although not directly looking at weight gain, data from the UK found that lower education was an independent predictor of less favorable weight management behaviors $(\beta=-.069, p=.003$ ) during COVID-19 self-quarantine [33]. Additional data from across the USA indicated that lower-income counties showed higher patronage of unhealthy eating establishments during the COVID-19 pandemic [63]. The extensive dataset from France indicated that higher incomes were associated with more favorable modifications of nutritional behaviors when compared to lower incomes [10]. Whether or not socio-economic status is a moderating variable between COVID-19 self-quarantine and weight gain is yet to be determined.

\section{Sleep Behaviors}

Alterations in sleep patterns have been reported during COVID-19 self-quarantine, with some data indicating that sleep hours have increased [16, 27]. The relationship between sleep duration and weight gain is a U-shaped relationship such that when sleep duration increases beyond a certain level, it then predicts weight gain [73]. Although sleep duration may have increased, sleep during COVID-19 self-quarantine has been reported to be filled with sleep disturbances and poor quality $[16,27,48]$. For instance, one study reported that $63.2 \%$ of subjects reported sleep disturbances during the pandemic versus only $53 \%$ before the pandemic [16]. Decreased sleep quality independently predicts COVID-19 self-quarantine weight gain $[20,28]$. Data from Italy revealed that within the $45 \%$ of participants who experienced a worsening sleep quality, an average weight gain of .5 $\mathrm{kg}$ was observed [20]. However, in participants who reported increased sleep quality, no weight gain was reported. Pre-COVID-19 pandemic data reveals that decreased sleep quality affects physical functioning during the subsequent day leading to sedentary behaviors [74].

\section{Conclusion}

The COVID-19 pandemic increases the risk of weight gain in specific individuals. Identified risk factors for weight gain during COVID-19 self-quarantine are the following: increased sedentary behaviors, decreased physical activity, increased snacking frequency (particularly after dinner), increased alcohol intake, decreased water intake, emotional eating, decreased sleep quality, and being overweight/obese. Average weight gain during the COVID-19 self-quarantine is similar to holiday weight gain [75]. Holiday weight gain may provide insight into unanswered questions about weight gained during the COVID-19 pandemic. For example, we know that weight gained during the holidays is not subsequently lost and that 
holiday weight gain contributes to more than half of annual weight gain in adults [76]. It is not clear if weight gained during the COVID-19 pandemic will subsequently be lost. Indeed, the duration of the initial lockdown period might have been sufficient for modified habits to settle in some individuals [77]. For instance, one dataset out of China looked at any possible lingering eating behaviors that stayed after lockdowns were lifted and found that people still followed certain dietary behaviors to cope with the COVID-19 pandemic [78]. Additionally, one study reported that within those who gained weight during COVID-19 self-quarantine, only rarely did they lose weight after peak lockdown eased [75]. Thus, a concern is that COVID-19-related weight increases will add to the annual holiday weight gain in 2020 and 2021, putting people at a greater risk for metabolic disorders. Having identified risk factors for weight gain during the COVID-19 pandemic, practitioners and researchers should devise plans to help those who have gained weight re-learn weight management/weight loss strategies.

A few challenges have emerged within the COVID-19 weight gain literature. First, identifying the exact amount of weight a person may gain during the COVID-19 self-quarantine is difficult as containment strategies are not universal throughout the world. Secondly, the timeframe of body weight being reported varied from one study to another, translating to some participants under self-quarantine guidelines much longer than others. Lastly, almost all data on weight gain and COVID-19 are self-report data. One study showed that many participants think they have gained more weight during COVID-19 than they did [79]. Thus, interpreting weight change data from the COVID-19 pandemic should be done with caution.

\section{References}

1. Velavan TP, Meyer CG. The COVID-19 epidemic. Tropical Med Int Health. 2020;25(3):278-80.

2. Fink S Worst-case estimates for US coronavirus deaths. New York Times. Published March 2020;13. https://www.nytimes.com/2020/ 03/13/us/coronavirus-deaths-estimate.html\#commentsContainer. Accessed 15 April 2021.

3. McIntosh K, Hirsch MS, Bloom A. Coronavirus disease 2019 (COVID-19). UpToDate Hirsch MS Bloom. 2020;5:1.

4. Saez M, Tobias A, Varga D, Barceló MA. Effectiveness of the measures to flatten the epidemic curve of COVID-19. The case of Spain. Sci Total Environ. 2020;138761.

5. Bhutani S, Cooper JA. COVID-19 related home confinement in adults: weight gain risks and opportunities. Obesity. 2020;28: 1576-7.

6. He M, Xian Y, Lv X, He J, Ren Y. Changes in body weight, physical activity, and lifestyle during the semi-lockdown period after the outbreak of COVID-19 in China: an online survey.
Disaster Med Public Health Prep 2020:1-6. https://doi.org/10. 1017/dmp.2020.237

7. Pellegrini M, Ponzo V, Rosato R, Scumaci E, Goitre I, Benso A, et al. Changes in weight and nutritional habits in adults with obesity during the "lockdown" period caused by the COVID-19 virus emergency. Nutrients. 2020;12(7):2016.

8. Reyes-Olavarría D, Latorre-Román PÁ, Guzmán-Guzmán IP, Jerez-Mayorga D, Caamaño-Navarrete F, Delgado-Floody P. Positive and negative changes in food habits, physical activity patterns, and weight status during COVID-19 confinement: associated factors in the Chilean population. Int J Environ Res Public Health. 2020;17(15):5431.

9. Rodríguez-Pérez C, Molina-Montes E, Verardo V, Artacho R, García-Villanova B, Guerra-Hernández EJ, et al. Changes in dietary behaviours during the COVID-19 outbreak confinement in the Spanish COVIDiet study. Nutrients. 2020;12(6):1730.

10. Deschasaux-Tanguy M, Druesne-Pecollo N, Esseddik Y, de Edelenyi FS, Alles B, Andreeva VA, et al. Diet and physical activity during the COVID-19 lockdown period (March-May 2020): results from the French NutriNet-Sante cohort study. Am J Clin Nutr. 2020;113(4):924-938.

11. Ghosal S, Arora B, Dutta K, Ghosh A, Sinha B, Misra A. Increase in the risk of type 2 diabetes during lockdown for the COVID19 pandemic in India: a cohort analysis. Diabetes Metab Syndr Clin Res Rev. 2020;14(5):949-52.

12. Zhu Q, Li M, Ji Y, Shi Y, Zhou J, Li Q, et al. "Stay-at-home" lifestyle effect on weight gain during the COVID-19 outbreak confinement in China. Int J Environ Res Public Health. 2021;18(4): 1813.

13. Kalligeros M, Shehadeh F, Mylona EK, Benitez G, Beckwith CG, Chan PA, et al. Association of obesity with disease severity among patients with coronavirus disease 2019. Obesity. 2020;28(7):12004.

14. Ryan DH, Ravussin E, Heymsfield S. COVID 19 and the patient with obesity-the editors speak out. Obesity (Silver Spring, Md.) 2020;28(5):847.

15. Ammar A, Brach M, Trabelsi K, Chtourou H, Boukhris O, Masmoudi L, et al. Effects of COVID-19 home confinement on eating behaviour and physical activity: results of the ECLBCOVID19 international online survey. Nutrients. 2020;12(6):1583.

16. Ismail LC, Osaili TM, Mohamad MN, Al Marzouqi A, Jarrar AH, Zampelas A, et al. Assessment of eating habits and lifestyle during coronavirus pandemic in the MENA region: a cross-sectional study. Br J Nutr 2020:1-30. https://doi.org/10.1017/S0007114520004547

17. Alfawaz H, Amer OE, Aljumah AA, Aldisi DA, Enani MA, Aljohani NJ, Alotaibi NH, Alshingetti N, Alomar SY, Khattak MNK, Sabico S, al-Daghri NM Effects of home quarantine during COVID-19 lockdown on physical activity and dietary habits of adults in Saudi Arabia. Sci Rep 2021;11(1):1-7, 5904.

18. Fitbit I. The impact of coronavirus on global activity. Available at: https://blog.ftbit.com/covid-19-global-activity/. Accessed April 1st, 2021.

19. Ammar A, Brach M, Trabelsi K, Chtourou H, Boukhris O, Masmoudi L, et al. Effects of COVID-19 home confinement on social participation and life satisfaction: preliminary results of the ECLB-COVID19 international online-survey. medRxiv 2020. https://doi.org/10.1101/2020.05.05.20091066

20. Micheletti Cremasco M, Mulasso A, Moroni A, Testa A, Degan R, Rainoldi A, et al. Relation among perceived weight change, sedentary activities and sleep quality during COVID-19 lockdown: a study in an academic community in Northern Italy. Int J Environ Res Public Health. 2021;18(6):2943.

21. Sánchez E, Lecube A, Bellido D, Monereo S, Malagón MM, Tinahones FJ. Leading factors for weight gain during COVID-19 lockdown in a Spanish population: a cross-sectional study. Nutrients. 2021;13(3):894. 
22. Boulos R, Vikre EK, Oppenheimer S, Chang H, Kanarek RB. ObesiTV: how television is influencing the obesity epidemic. Physiol Behav. 2012;107(1):146-53.

23. Pietiläinen KH, Kaprio J, Borg P, Plasqui G, Yki-Järvinen H, Kujala UM, et al. Physical inactivity and obesity: a vicious circle. Obesity. 2008;16(2):409-14.

24. Amaro-Gahete FJ, Jurado-Fasoli L, De-la-O A, Gutierrez Á, Castillo MJ, Ruiz JR. Accuracy and validity of resting energy expenditure predictive equations in middle-aged adults. Nutrients. 2018;10(11):1635.

25. Kriaucioniene V, Bagdonaviciene L, Rodríguez-Pérez C, Petkeviciene J. Associations between changes in health behaviours and body weight during the COVID-19 quarantine in Lithuania: the Lithuanian COVIDiet Study. Nutrients. 2020;12(10):3119.

26. Phillipou A, Meyer D, Neill E, Tan EJ, Toh WL, Van Rheenen TE, et al. Eating and exercise behaviors in eating disorders and the general population during the COVID-19 pandemic in Australia: initial results from the COLLATE project. Int $\mathrm{J}$ Eat Disord. 2020;53(7):1158-65.

27. Di Renzo L, Gualtieri P, Pivari F, Soldati L, Attinà A, Cinelli G, et al. Eating habits and lifestyle changes during COVID-19 lockdown: an Italian survey. J Transl Med. 2020;18:1-15.

28. Zachary Z, Brianna F, Brianna L, Garrett P, Jade W, Alyssa D, et al. Self-quarantine and weight gain related risk factors during the COVID-19 pandemic. Obes Res Clin Pract. 2020;14(3):210-6.

29. Lee I, Djoussé L, Sesso HD, Wang L, Buring JE. Physical activity and weight gain prevention. JAMA. 2010;303(12):1173-9.

30. Panahi S, Tremblay A. Sedentariness and health: is sedentary behavior more than just physical inactivity? Front Public Health. 2018;6:258.

31. Gasmi A, Noor S, Tippairote T, Dadar M, Menzel A, Bjørklund G. Individual risk management strategy and potential therapeutic options for the COVID-19 pandemic. Clin Immunol 2020:108409. https://doi.org/10.1016/j.clim.2020.108409

32. AlMughamis N, AlAsfour S, Mehmood S. Poor eating habits and predictors of weight gain during the COVID-19 quarantine measures in Kuwait: a cross sectional study. F1000Research. 2020;9(914):914.

33. Robinson E, Boyland E, Chisholm A, Harrold J, Maloney NG, Marty L, et al. Obesity, eating behavior and physical activity during COVID-19 lockdown: a study of UK adults. Appetite. 2021;156: 104853.

34. Bracale R, Vaccaro CM. Changes in food choice following restrictive measures due to COVID-19. Nutr Metab Cardiovasc Dis. 2020;30(9):1423-6.

35. Rhodes JM, Subramanian S, Laird E, Griffin G, Kenny RA. Perspective: Vitamin D deficiency and COVID-19 severityplausibly linked by latitude, ethnicity, impacts on cytokines, ACE2 and thrombosis. J Intern Med. 2021;289(1):97-115.

36. Carroll N, Sadowski A, Laila A, Hruska V, Nixon M, Ma DW, et al. The impact of COVID-19 on health behavior, stress, financial and food security among middle to high income Canadian families with young children. Nutrients. 2020;12(8):2352.

37. Sidor A, Rzymski P. Dietary choices and habits during COVID-19 lockdown: experience from Poland. Nutrients. 2020;12(6):1657.

38. Mattes RD. Snacking: a cause for concern. Physiol Behav. 2018;193:279-83

39. Hills AP, Byrne NM, Lindstrom R, Hill JO. 'Small changes' to diet and physical activity behaviors for weight management. Obes Facts. 2013;6(3):228-38.

40. Loboda A, Kraft WK, Fine B, Joseph J, Nebozhyn M, Zhang C, et al. Diurnal variation of the human adipose transcriptome and the link to metabolic disease. BMC Med Genet. 2009;2(1):7.

41. Tu BP, Kudlicki A, Rowicka M, McKnight SL. Logic of the yeast metabolic cycle: temporal compartmentalization of cellular processes. Science. 2005;310(5751):1152-8.
42. Boschmann M, Steiniger J, Hille U, Tank J, Adams F, Sharma AM, et al. Water-induced thermogenesis. J Clin Endocrinol Metab. 2003;88(12):6015-9.

43. Dennis EA, Dengo AL, Comber DL, Flack KD, Savla J, Davy KP, et al. Water consumption increases weight loss during a hypocaloric diet intervention in middle-aged and older adults. Obesity. 2010;18(2):300-7.

44. Rolland B, Haesebaert F, Zante E, Benyamina A, Haesebaert J, Franck N. Global changes and factors of increase in caloric/salty food intake, screen use, and substance use during the early COVID19 containment phase in the general population in France: survey study. JMIR Public Health Surveill. 2020;6(3):e19630.

45. Stanton R, To QG, Khalesi S, Williams SL, Alley SJ, Thwaite TL, et al. Depression, anxiety and stress during COVID-19: associations with changes in physical activity, sleep, tobacco and alcohol use in Australian adults. Int J Environ Res Public Health. 2020;17(11): 4065.

46. Chodkiewicz J, Talarowska M, Miniszewska J, Nawrocka N, Bilinski P. Alcohol consumption reported during the COVID-19 pandemic: the initial stage. Int J Environ Res Public Health. 2020;17(13):4677.

47. Traversy G, Chaput J. Alcohol consumption and obesity: an update. Curr Obes Rep. 2015;4(1):122-30.

48. Huang Y, Zhao N. Generalized anxiety disorder, depressive symptoms and sleep quality during COVID-19 outbreak in China: a webbased cross-sectional survey. Psychiatry Res. 2020;288:112954.

49. Rajkumar RP. COVID-19 and mental health: a review of the existing literature. Asian J Psychiatr. 2020;52:102066.

50. Brooks SK, Webster RK, Smith LE, Woodland L, Wessely S, Greenberg N, et al. The psychological impact of quarantine and how to reduce it: rapid review of the evidence. Lancet. 2020;395(10227):912-20.

51. Lai J, Ma S, Wang Y, Cai Z, Hu J, Wei N, et al. Factors associated with mental health outcomes among health care workers exposed to coronavirus disease 2019. JAMA Netw Open. 2020;3(3):e203976.

52. Xiang Y, Jin Y, Cheung T. Joint international collaboration to combat mental health challenges during the coronavirus disease 2019 pandemic. JAMA Psychiatry. 2020;77(10):989-90.

53. Cinelli M, Quattrociocchi W, Galeazzi A, Valensise CM, Brugnoli E, Schmidt AL, et al. The COVID-19 social media infodemic. Sci Rep. 2020;10(1):1-10.

54. Gao J, Zheng P, Jia Y, Chen H, Mao Y, Chen S, et al. Mental health problems and social media exposure during COVID-19 outbreak. PLoS One. 2020;15(4):e0231924.

55. Yannakoulia M, Panagiotakos DB, Pitsavos C, Tsetsekou E, Fappa E, Papageorgiou $\mathrm{C}$, et al. Eating habits in relations to anxiety symptoms among apparently healthy adults. A pattern analysis from the ATTICA Study. Appetite. 2008;51(3):519-25.

56. Anton SD, Miller PM. Do negative emotions predict alcohol consumption, saturated fat intake, and physical activity in older adults? Behav Modif. 2005;29(4):677-88.

57. Maniscalco JW, Kreisler AD, Rinaman L. Satiation and stressinduced hypophagia: examining the role of hindbrain neurons expressing prolactin-releasing peptide or glucagon-like peptide 1 . Front Neurosci. 2013;6:199.

58. Razzoli M, Bartolomucci A. The dichotomous effect of chronic stress on obesity. Trends Endocrinol Metab. 2016;27(7):504-15.

59. Sominsky L, Spencer SJ. Eating behavior and stress: a pathway to obesity. Front Psychol. 2014;5:434.

60. Moynihan AB, Van Tilburg WA, Igou ER, Wisman A, Donnelly AE, Mulcaire JB. Eaten up by boredom: consuming food to escape awareness of the bored self. Front Psychol. 2015;6:369.

61. Frayn M, Knäuper B. Emotional eating and weight in adults: a review. Curr Psychol. 2018;37(4):924-33.

62. Zhang J, Zhang Y, Huo S, Ma Y, Ke Y, Wang P, et al. Emotional eating in pregnant women during the COVID-19 pandemic and its 
association with dietary intake and gestational weight gain. Nutrients. 2020;12(8):2250.

63. Ashby NJ. Impact of the COVID-19 pandemic on unhealthy eating in populations with obesity. Obesity. 2020;28(10):1802-5.

64. Cooksey-Stowers K, Schwartz MB, Brownell KD. Food swamps predict obesity rates better than food deserts in the United States. Int J Environ Res Public Health. 2017;14(11):1366.

65. Poelman MP, Gillebaart M, Schlinkert C, Dijkstra SC, Derksen E, Mensink F, et al. Eating behavior and food purchases during the COVID-19 lockdown: a cross-sectional study among adults in the Netherlands. Appetite. 2021;157:105002.

66. Ganley RM. Emotion and eating in obesity: a review of the literature. Int J Eat Disord. 1989;8(3):343-61.

67. Cotter EW, Kelly NR. Stress-related eating, mindfulness, and obesity. Health Psychol. 2018;37(6):516-25.

68. Puhl RM, Himmelstein MS, Pearl RL. Weight stigma as a psychosocial contributor to obesity. Am Psychol. 2020;75(2):274-89.

69. Brown A, Flint SW, Kalea AZ, O'Kane M, Williams S, Batterham RL. Negative impact of the first COVID-19 lockdown upon healthrelated behaviours and psychological wellbeing in people living with severe and complex obesity in the UK. EClinicalMedicine. 2021;34:100796

70. Rubino F, Puhl RM, Cummings DE, Eckel RH, Ryan DH, Mechanick JI, et al. Joint international consensus statement for ending stigma of obesity. Nat Med. 2020;26(4):485-97.

71. Puhl RM, Lessard LM, Larson N, Eisenberg ME, NeumarkStzainer D. Weight stigma as a predictor of distress and maladaptive eating behaviors during COVID-19: longitudinal findings from the EAT study. Ann Behav Med. 2020;54(10):738-46.

72. Bann D, Villadsen A, Maddock J, Hughes A, Ploubidis G, Silverwood R, et al. Changes in the behavioural determinants of health during the coronavirus (COVID-19) pandemic: gender, socioeconomic and ethnic inequalities in 5 British cohort studies. J Epidemiol Community Health. 2020. https://doi.org/10.1136/jech2020-215664

73. Theorell-Haglöw J, Berglund L, Berne C, Lindberg E. Both habitual short sleepers and long sleepers are at greater risk of obesity: a population-based 10-year follow-up in women. Sleep Med. 2014;15(10):1204-11.

74. Sher L. COVID-19, anxiety, sleep disturbances and suicide. Sleep Med. 2020;70:124.

75. Bhutani S, MRv D, Cooper JA. Longitudinal weight gain and related risk behaviors during the COVID-19 pandemic in adults in the US. Nutrients. 2021;13(2):671.

76. Yanovski JA, Yanovski SZ, Sovik KN, Nguyen TT, O'Neil PM, Sebring NG. A prospective study of holiday weight gain. N Engl J Med. 2000;342:861-7.

77. Lally P, Van Jaarsveld CH, Potts HW, Wardle J. How are habits formed: modelling habit formation in the real world. Eur J Soc Psychol. 2010;40(6):998-1009.

78. Zhang J, Zhao A, Ke Y, Huo S, Ma Y, Zhang Y, et al. Dietary behaviors in the post-lockdown period and its effects on dietary diversity: the second stage of a nutrition survey in a longitudinal Chinese study in the COVID-19 era. Nutrients. 2020;12(11):3269.

79. Keel PK, Gomez MM, Harris L, Kennedy GA, Ribeiro J, Joiner TE Gaining "The quarantine 15:" perceived versus observed weight changes in college students in the wake of COVID-19. Int J Eat Disord. 2020;53(11):1801-8.

Publisher's Note Springer Nature remains neutral with regard to jurisdictional claims in published maps and institutional affiliations. 